\title{
Subsurface Based Contaminant Transport Modelling of SDS $\left(\mathrm{NaC}_{12} \mathrm{~h}_{25} \mathrm{SO}_{4}\right)$
}

\author{
P. Oliver jayaprakash, C. Mekala, M. Vishnu Priyan
}

\begin{abstract}
Subsurface contamination by emerging contaminants from inappropriate effluent discharge is one of the serious issues directly affecting the quality of groundwater. This study is aimed at transport and transformations of anionic surfactant (SDS). Sodium Dodecyl Sulfate [ $\left.\mathrm{NaC}_{12} \mathrm{H}_{25} \mathrm{SO}_{4}\right]$ from grey wastewater containing detergents in unsaturated soils and its impacts on groundwater. HYDRUS-1D model to predict the transport mechanisms was developed. In this regard, surfactant concentrations for SDS from the sewage treatment plant of KCET, Virudhunagar was taken for evaluation. This research work reveals that inlet, outlet, sludge with ample quantities of SDS concentrations $(13,9.55$ and $15.67 \mathrm{mg} / \mathrm{L})$. Soil irrigated with sewage was taken as primary sample. Soil column experiments were conducted first with tracer to calculate the dispersion at a flow rate of $1 \mathrm{~cm} / \mathrm{h}$, estimated to be $3.1 \mathrm{~cm}$. A series of transport experiments were started with $10 \mathrm{mg} / \mathrm{L}$ of SDS to comprehend the sorption tied biodegradation. It was observed that leaching phenomenon was the dominant process when compared to biodegradation and sorption. An initial concentration of 13.44 $\mathrm{mg} / \mathrm{L}$ was administered and found $12 \mathrm{mg} / \mathrm{L}$ at the outlet. Hence, $1.44 \mathrm{mg} / \mathrm{L}$ underwent sorption and biodegradation. The model estimated linear sorption parameter with first order degradation coefficient $0.131 \mathrm{cc} / \mathrm{g}$ and $0.01 / \mathrm{h}$. The calibrated HYDRUS model was adopted to study the various scenarios with GWT depth of $30 \mathrm{~m}$. The simulated SDS concentration at GWT of $30 \mathrm{~m}$ is $4.13 \mathrm{mg} /$ litre.
\end{abstract}

Key words: SDS, Soil column, HYDRUS-1D, Contaminant transport, GWT, Wastewater.

\section{INTRODUCTION} $\mathrm{R}_{\text {apid growth and mounting production of chemicals over }}$ decades end up in discharge of numerous chemical compounds into atmosphere. Wastewater is mixture of black and grey water. It is desirable to treat these separately to reduce the pollution load coming on the treatment systems. Grey water constitutes $50 \%$ to $80 \%$ of domestic wastewater resulting in higher concentration of surfactants (chen et al., 2013). Pharmaceutical products and special care products are found in the environment in case of partial treated wastewater discharged to the soil was critically reviewed by Verlicchi and Zambello 2015. Most of the usual sewage treatment systems such as Biological Aerated Filter (BAF), Sequencing Batch Reactor (SBR), Rotating Biological Contactor (RBC),

Revised Manuscript Received on February 05, 2020.

* Correspondence Author

Dr. P. Oliver jayaprakash*, Professor, Department of Civil Engineering, Sethu Institute of Technology (Autonomous) Kariapatti, Tamil Nadu, India. Email: poliver@sethu.ac.in

Dr. C. Mekala. Associate Professor, Department of Civil Engineering, Sethu Institute of Technology(Autonomous) Kariapatti, Tamil Nadu, India. Email: mekala@sethu.ac.in

M. Vishnu Priyan, Research Scholar, Department of Civil Engineering, KCET, Virdhunagar, Tamil Nadu, India. Email: visman96@gmail.com

(C) The Authors. Published by Blue Eyes Intelligence Engineering and Sciences Publication (BEIESP). This is an open access article under the CC BY-NC-ND license (http://creativecommons.org/licenses/by-nc-nd/4.0/)

Sand Filtration, Ultra Filtration, Coagulation and Flocculation and Electro-Coagulation are effective in removing organic matter and nutrients to a large extent (Liu et al.,2010). However these methods are incapable of removing several surfactants and PCPs. Besides excessive operation and maintenance cost, the present systems require uninterrupted power. Presence of high concentration detergents in grey water makes it worse. It is contributed by sodium dodecyl sulphate (SDS), an anionic surfactant (29.22\%) constitute for the maximum constituents' content. Priti and Hemangi 2012 states that alumina could remove SDS with $99.3 \%$ efficiency by chemical treatment. Limited studies reported deprivation of SDS under aerobic conditions, anaerobic conditions and in bio-filtration. Studies reported that the SDS adsorption onto the soil (Ram Prasad \& Philip et al., 2013). Several models and HYDRUS based simulations were established to quantify the water flow and solute movement through the unsaturated and saturated zones. However, several modelling studies on Nitrate transport through saturated and unsaturated porous media considering various numerous physico-chemical processes such as advection, dispersion, sorption, mineralization, nitrification, denitrification, volatilization, atmospheric deposition and plant nutrient uptake were reported. Simulation models for water flow and SDS transport are restricted in their applicability to soil heterogeneity, complex bio-geo-chemical reactions, and field applications, consideration of all transport and transformations, a combined unsaturated and saturated system and advanced bio kinetic models for biodegradation. However experimental validations for these models are weak.

Hence developing a comprehensive numerical model is necessary. HYDRUS based simulations are need of the hour to address various biological and hydrodynamic interactions in SDS transport through the unsaturated zone. This work aimed at developing a strategy for safe wastewater reuse for irrigation with specific focus on Sodiumdodecyl Sulfate, transport and transformations in unsaturated porous media. The specific objectives are;

- To study the transport dynamics of SDS through unsaturated soils with sorption and biodegradation mechanisms.

- To develop a mathematical model to understand the surfactants transport and transformations in soil.

\section{MATERIAL AND METHODS}

\section{A. Characterization of Soil and Wastewater}

Sewage samples from the STP of Kamaraj College of Engineering and Technology at Virudhunagar (KCET) is used for study. 


\section{Subsurface Based Contaminant Transport Modelling of SDS $\left(\mathrm{Nac}_{12} \mathbf{h}_{25} \mathrm{SO}_{4}\right)$}

The STP commissioned in 2010 and operated for treatment of grey water generated within the campus. Wastewater characteristics such as COD, BOD, pH, TDS, TSS, Ammonium, nitrates, metals such as Lead, Zinc and SDS were analyzed. Soil sample was collected from $1 \mathrm{~m}$ depth from a nearby STP and from the site irrigated with partially treated sewage from KCET at Virudhunagar, South India. A surface and deep soil mixture were collected and a portion passed through $2 \mathrm{~mm}$ sieve was adopted for experiment. The soil was autoclaved at a temperature of $121^{\circ} \mathrm{C}$ cooled for 15 minutes and stored in plastic covers for future studies.

Soil organic content and moisture content measured by Dry ignition method for three random samples. Soil extraction for analyzing ammonium and nitrate with $2 \mathrm{M} \mathrm{KCl}$ was done.

Particle size distribution, Dry bulk density, Specific gravity, Permeability, $\mathrm{pH}$, and Soil hydraulic parameters such as van Genuchten parameters such as residual and saturated water content were collected from secondary data.

\section{B. SDS analysis Present in Wastewater}

A Spectrophotometric method for the determination of sodium dodecyl sulphate (SDS), an anionic surfactant (AS) is adopted (Ramprasad et al., 2016). SDS forms a yellow colored complex with acridine orange (ACO), a cationic dye. The complex is extracted in toluene. The absorbance of the complex in toluene layer is measured at maximum wavelength $\left(\lambda_{\max }\right)$ of $467 \mathrm{~nm}$. The calibration curve is linear in the range of $0-6 \mathrm{ppm}$ of SDS concentration.

\section{Continuous Column Studies}

A series of column experiments in an acrylic column of length $50 \mathrm{~cm}$ and diameter $5.2 \mathrm{~cm}$ were performed. The feed was supplied with peristaltic pump at a pore velocity of $0.153 \mathrm{~cm} / \mathrm{min}$. The column was wet packed with soil slurry to produce a homogenous medium avoiding the formation of stratifying layers and preferential flow paths. The column was equilibrated with mineral medium containing the washed out bacteria during initial feeding until it reached a steady state.

The following column experiments were conducted: (i) blank soil column with $\mathrm{NaCl}$ as tracer; (ii) soil column transport studies with SDS. The SDS and $\mathrm{NaCl}$ containing feed were added to the column at $10 \mathrm{mg} / \mathrm{L}$ and SDS at 10 $\mathrm{mg} / \mathrm{L}$. The outlet concentrations for SDS and $\mathrm{NaCl}$ at $35 \mathrm{~cm}$ depth of soil column were observed with respect to time along with pore velocity monitoring. The experimental setups with operating conditions were shown in Fig.1.

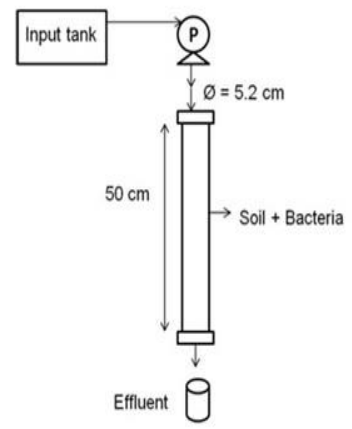

\begin{tabular}{|l|l|}
\hline Parameters & Soil column \\
\hline Porosity & 0.324 \\
\hline Hydraulic conductivity & $7.75 \times 10-3 \mathrm{~cm} / \mathrm{s}$ \\
\hline Bulk density & $1.53 \mathrm{~kg} / \mathrm{m} 3$ \\
\hline$D_{60}$ mean grain size & $3 \mathrm{~mm}$ \\
\hline Pore volume & 0.16 day \\
\hline
\end{tabular}

Fig.1(a) Experimental soil column setup (b) Operation conditions

\section{III.MODEL DEVELOPMENT USING HYDRUS 1D}

Flow and transport through unsaturated zone is visualised by Richards's model (Simunek et al., 2008) The unsaturated soil hydraulic properties, $\theta(\mathrm{h})$ and $\mathrm{K}(\mathrm{h})$, are in general highly nonlinear functions of the pressure head. The soil water retention, $\theta(\mathrm{h})$, and hydraulic conductivity, $\mathrm{K}(\mathrm{h})$, functions (Brooks \& Corey 1964) are given by

where,

$$
\left(\frac{\partial \theta}{\partial h}\right) \frac{\partial h}{\partial t}=\frac{\partial}{\partial z}\left[K(h) \frac{\partial h}{\partial z}-K(h)\right]
$$

K - Hydraulic conductivity of the soil (L / T),

$\theta$ - Volumetric soil moisture content,

$\mathrm{h}$ - Pressure head (L),

$\mathrm{z}$ - depth of soil (positive downward) (L)

$\mathrm{t}$ - time $(\mathrm{T})$

Time and distance (z-co-ordinate), Pressure head, volumetric water content and Hydraulic conductivity. Van Genuchtan solved the Richards equation using the relationship between $\theta$ and $h$.

$$
\theta=\theta_{r}+\frac{\theta_{s}-\theta_{r}}{\left[1+(a h)^{\beta}\right]^{n}}
$$

Relation between K and $\theta$ (Van Genuchten, 1980)

$$
K\left(S_{e}\right)=K_{s} S_{e}^{1 / 2}\left[1-\left(1-S_{e}^{1 / 0}\right)^{o}\right]^{2}
$$

Where,

$$
S_{e}=\frac{\theta-\theta_{r}}{\theta_{s}-\theta_{r}}
$$

Where,

$$
\begin{aligned}
& \eta=1-1 / \beta . \\
& \alpha-\text { is related to the inverse of the air entry suction, } \\
& \alpha>0,\left(\mathrm{~cm}^{-1}\right) \\
& \beta-\text { is a measure of the pore-size distribution, } b>1 \\
& \text { (dimensionless) }
\end{aligned}
$$

\section{IV.RESULTS AND DISCUSSION}

\section{A. Soil Physicochemical Characteristics}

The initial soil physicochemical characteristics such as $\mathrm{pH}$, EC, porosity, particle size distribution and specific gravity were analyzed as per (BIS, 1989) standard methods and presented in Table I. Soil was characterised as sandy soil with bulk density of $1.53 \mathrm{~kg} / \mathrm{m}^{3}$ and permeability of $0.01225 \mathrm{~cm} / \mathrm{s}$.

Table-I: Soil Physiochemical Characteristics

\begin{tabular}{|c|c|}
\hline Parameters & Results \\
\hline Void Ratio & 0.48 \\
\hline Porosity & 0.324 \\
\hline Specific Gravity & 2.22 \\
\hline Moisture Content & 0.04 \\
\hline Bulk Density & $1.53 \mathrm{~kg} / \mathrm{m} 3$ \\
\hline Dry Density & $1.47 \mathrm{~kg} / \mathrm{m} 3$ \\
\hline Permeability & $0.01225 \mathrm{~cm} / \mathrm{s}$ \\
\hline
\end{tabular}




\begin{tabular}{|c|c|}
\hline $\mathrm{pH}$ & 10.43 \\
\hline Soil Type & Sandy Soil \\
& D10 $=0.3 \mathrm{~mm}$ \\
& D30 $=0.7 \mathrm{~mm}$ \\
& D60 $=3 \mathrm{~mm}$ \\
$\mathrm{Cu}=9$ \\
$\mathrm{Cc}=0.9$
\end{tabular}

\section{B. Wastewater Characteristics}

The initial characteristics of waste water like $\mathrm{pH}$, Total Conductivity, Total solids, COD, BOD were analysed as per (APHA 2009) standard methods given in Table II.

Table-II: Wastewater Charateristics

\begin{tabular}{|c|c|}
\hline Parameters & Results \\
\hline $\mathrm{pH}$ & 8.23 \\
\hline Total Solids & $815 \mathrm{mg} / \mathrm{l}$ \\
\hline Nitrates & $22 \mathrm{mg} / \mathrm{l}$ \\
\hline Total dissolved solids & $625 \mathrm{mg} / \mathrm{l}$ \\
\hline COD & $137.6 \mathrm{mg} / \mathrm{l}$ \\
\hline BOD & $22 \mathrm{mg} / \mathrm{l}$ \\
\hline Ammonium & $4.36 \mathrm{mg} / \mathrm{l}$ \\
\hline
\end{tabular}

\section{SDS Analysis}

SDS Concentration in waste water, sludge and sludge applied soil is analyzed by digital photo calorimeter in visible range of wavelength $467 \mathrm{~mm}$ (Ramprasad et al., 2016). The permissible limit of SDS in wastewater is $1 \mathrm{mg} / \mathrm{l}$. It was observed that the treated wastewater, sludge and sludge amended soil has $9.55 \mathrm{mg} / \mathrm{L}, 15.67 \mathrm{mg} / \mathrm{L}$, and 9.12 $\mathrm{mg} / \mathrm{L}$ respectively as shown in Table III.

Table-III: SDS Concentration In Wastewater, Soil and Sludge

\begin{tabular}{|c|c|}
\hline SDS & $\begin{array}{c}\text { Concentration } \\
\text { (mg/l) }\end{array}$ \\
\hline Treated wastewater & 9.55 \\
\hline Sludge & 15.67 \\
\hline Wastewater irrigated soil & 9.12 \\
\hline Freshwater irrigated soil & 0.02 \\
\hline
\end{tabular}

\section{Tracer Study}

Tracer study is done using $\mathrm{NaCl}$ to find out the dispersion coefficient of SDS in soil particles. The result of breakthrough curve was shown in Fig. 2.
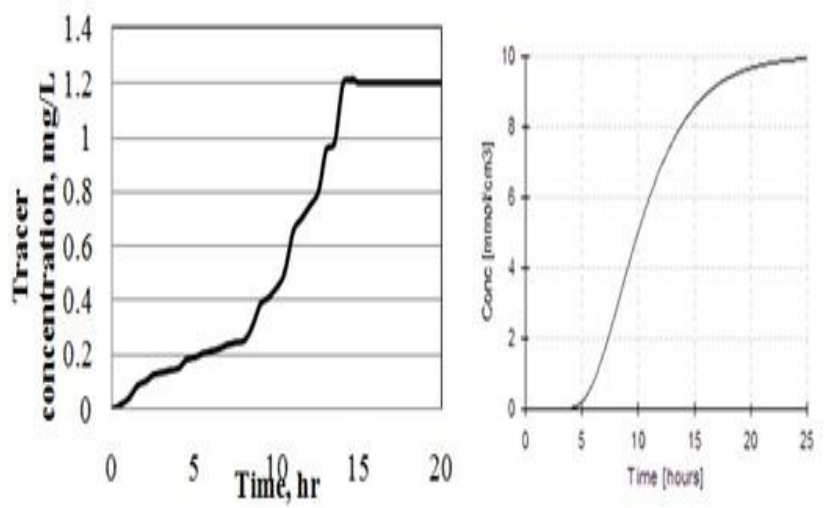

Fig. 2(a) Experimental Result of Tracer study (b) Model outcomes.
Breakthrough graph is drawn between SDS concentration Vs time. The contaminant dispersion in soil with respect to time. A smooth and S-shaped breakthrough profile was obtained. The longitudinal dispersivity $(\alpha)$ was estimated based on model calibration to be $0.73 \mathrm{~cm}$ from experimental tracer breakthrough graph. The tracer profile ensures a uniform flow and a homogeneous soil packing. From the above graph, it was inferred that the concentration of $\mathrm{NaCl}$ increases after 5 hours and it becomes constant at 25 hours with the final concentration is $5.4 \mathrm{mg} / \mathrm{l}$.

\section{E. Transport Study of Sorption Coupled Biodegradation of SDS}

Retarded transport of SDS by sorption and biodegradation was observed. The inlet SDS concentrations of $10 \mathrm{mg} / \mathrm{L}$ were used. The parameters such as adsorption coefficient, first order biodegradation constant were adopted from Harendra et al., 2012 for SDS. These parameters were used for mcalibration and validated with the experimental SDS breakthrough (BTC) profiles as shown in Fig.3. After calibration the model estimated parameter was compared with the assumed parameter from the literature as given in Table.IV.

Table-IV: Results of Tracer Study

\begin{tabular}{|l|l|l|}
\hline Parameter & $\begin{array}{l}\text { Literature } \\
\text { source } \\
\text { (Harendra } \text { et } \\
\text { al., 2012) }\end{array}$ & $\begin{array}{l}\text { Model } \\
\text { prediction }\end{array}$ \\
\hline $\begin{array}{l}\text { Van Genuchten Parameters ( Mekala } \text { et al., 2016) } \\
\alpha=0.0335(1 / \mathrm{cm}), \beta=2, \eta=0.5\end{array}$ \\
\hline $\begin{array}{l}\text { Sorption } \\
\text { coefficient }\end{array}$ & $3.93 \times 10^{-8} \mathrm{l} / \mathrm{mg}$ & $1.28 \times 10^{-5} \mathrm{l} / \mathrm{mg}$ \\
\hline $\begin{array}{l}\text { First order bio- } \\
\text { degrdaation }\end{array}$ & $0.77 \mathrm{mg} / \mathrm{L}$ & $1.23 \mathrm{mg} / \mathrm{L}$ \\
\hline
\end{tabular}

The model proposed under predicts the experimental data with an efficiency of 0.685 . The model under predicted the advection and dispersion flow but the biodegradation reactions was predicted well. It is observed in the experimental BTC where deviations are up to 35 hours which corresponds to flow properties and leaching. After which, the model prediction watches well with the experimental BTC corresponding to reactive transport due to biodegradation. The deviation is due to stabilisation and acclimatization of bacteria as well as the variations in initial water content and flow parameters. Also, SDS being an anion, the adherence to soil is low which tend to leaches out of the soil column. The behaviour of SDS was similar to nitrate anion as reported in Mekala et al., 2017. The leaching mechanism is not incorporated in the model.

The spatial retardation coefficient $\mathrm{R}$, for SDS obtained from the mathematical model was 0.42 which is very less. Osama and Erol 2010 reported that cationic surfactant showed high $\mathrm{R}$ value of 0.92 with soil particles due to high electrostatic attractive force between cationic and negative clay particles. Being an anion, the SDS tends to leach out of the soil rather than sorption. The initial concentration of SDS was obtained around 30 hrs. With this breakthrough analysis, it was found that leaching was the predominant process than biodegradation and sorption. 


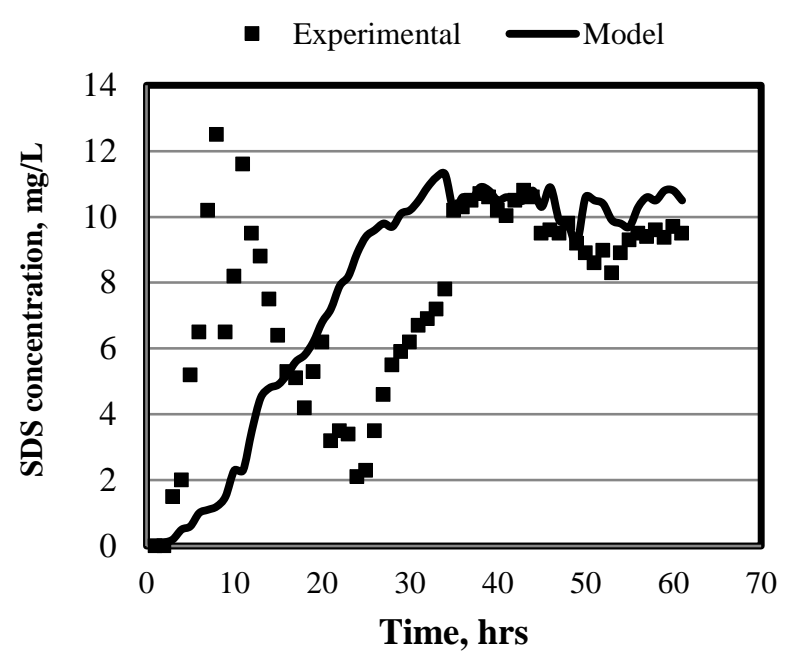

Fig.3 Result of SDS Transport Study compared with model

F. Modelling using HYDRUS-1D : Model Result for Tracer Study

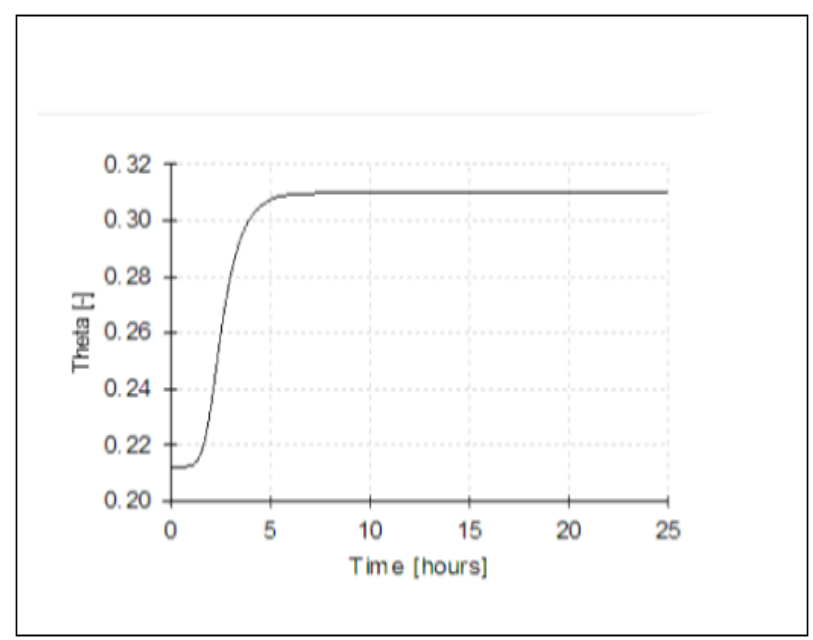

Fig.4. Water Content for Tracer study using HYDRUS model

From Fig.4, it is observed that the initial concentration of water content is 0.21 .After 1 hour, breakthrough curve starts and reaches saturation of 0.33 at 5 hours and becomes constant throughout the experiment.

\section{G. Model Results for Transport Study of SDS}

The initial concentration of SDS used for transport experiment was $13.44 \mathrm{mg} / \mathrm{l}$. Samples are taken at regular intervals and its concentration was measured. It was observed from Fig.5, that the concentration of SDS in column starts to increase at 5 hours interval of and saturated at 33 hours. The final concentration measured was 11.3 $\mathrm{mg} / \mathrm{l}$. So, $2.14 \mathrm{mg} / \mathrm{l}$ of SDS was consumed due to sorption and biodegradation at negligible concentrations. The model was calibrated with the experimental breakthrough curve and the Linear Sorption coefficient and first order degradation as shown in Table 4.

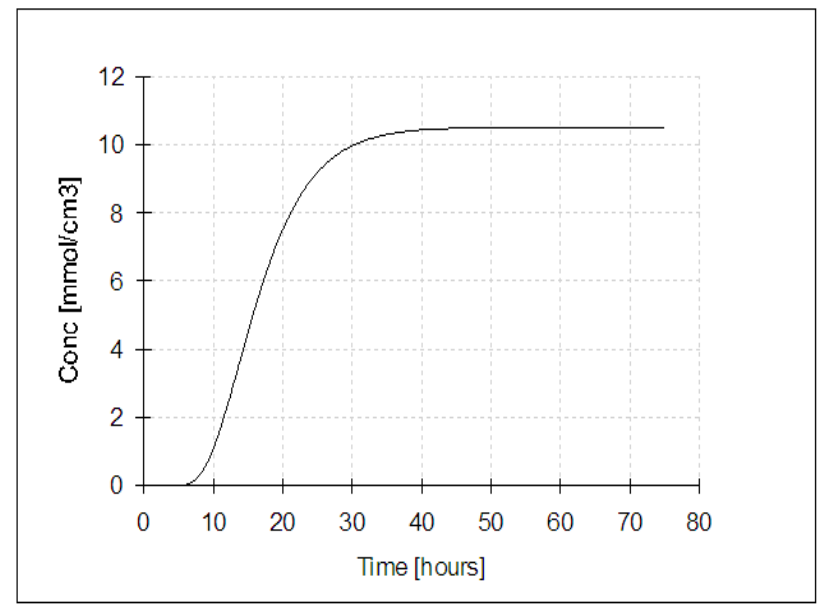

Fig.5 Model result for sorption with biodegradation of SDS

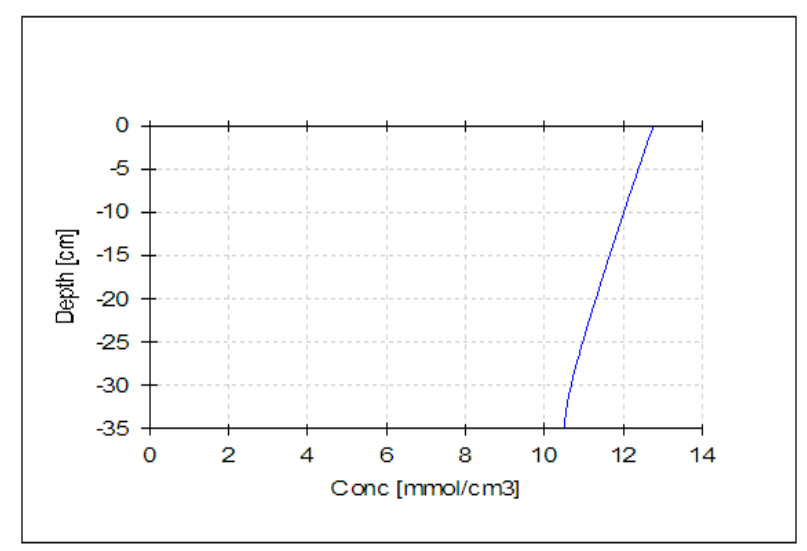

Fig.6 Model prediction for depth wise Concentration of SDS

\section{H. SDS Concentration profile with depth}

It was found from Fig.6, the spatial variation of SDS concentration at top surface was $13.44 \mathrm{mg} / \mathrm{l}$ and at the bottom was $11.2 \mathrm{mg} / \mathrm{l}$. It is showed that very high leaching potential for SDS rather than sorption or biodegradation.

\section{SCENARIO STUDY}

The model was calibrated and validated with experimental breakthrough curves and further used for different scenario studies. A scenario was performed to understand the leaching impact of SDS on groundwater at 30m depth. The results of model predictions for water content and SDS concentration are present in Fig.7 (a) \& (b). It was observed that for GWT of $30 \mathrm{~m}$ the optimum moisture content was 0.33 and reaches its saturation in 4 days. It was observed that for first 6 days there was no concentration of SDS leaching to GWT because all SDS are degraded by the soil microorganisms. But, after continuous irrigation with the sewage, the concentration of SDS gradually increase after 12 days, and became saturated at $4.33 \mathrm{mg} / \mathrm{l}$. However, this concentration will contaminate the groundwater. 


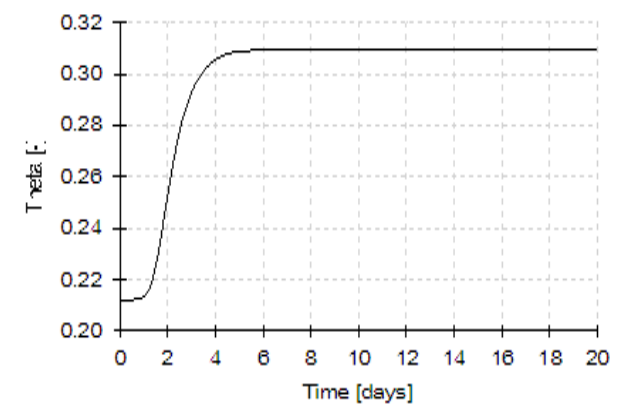

Fig. 7(a) Model prediction for Water Content variation

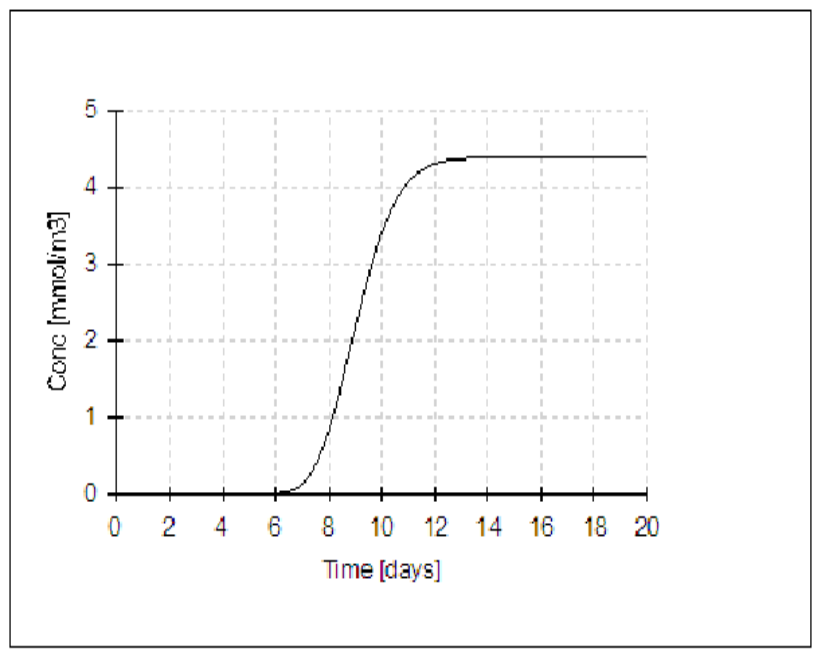

Fig. 7 (b) Model prediction for SDS Concentration

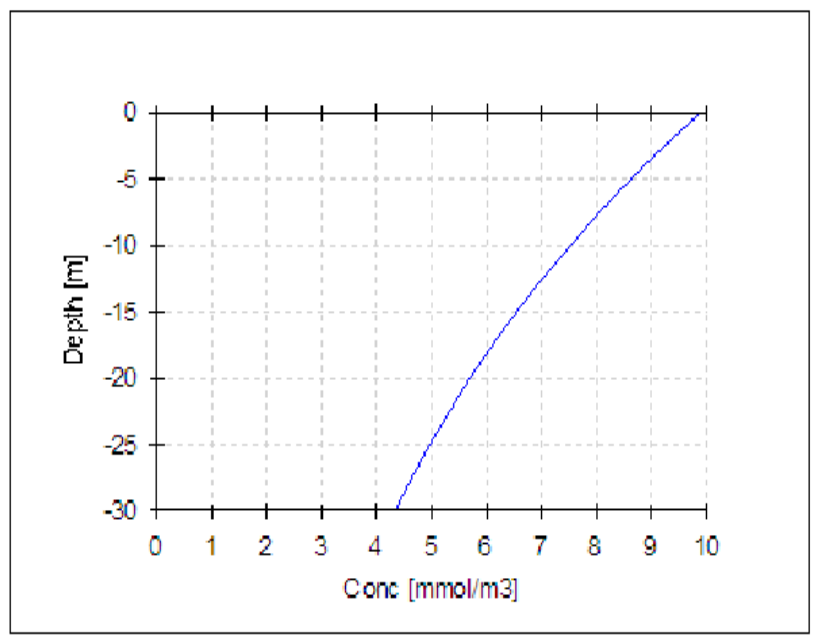

Fig.8 Model prediction for Depth wise concentration profile of SDS

Fig.8 shows the spatial variation of SDS concentration in soil profile. There was no SDS present at the top surface .While at depth of $5 \mathrm{~m}, 15 \mathrm{~m}, 30 \mathrm{~m}$; the SDS concentration was $8.6 \mathrm{mg} / \mathrm{l}, 6.5 \mathrm{mg} / \mathrm{l}$ and $4.33 \mathrm{mg} / \mathrm{l}$ respectively. Since here the concentration at $30 \mathrm{~m}$ is $4.33 \mathrm{mg} / \mathrm{l}$ is higher than the permissible limit of $1 \mathrm{mg} /$ lit. This may contaminate the GWT. Hence these mathematical modelling tools are used to identify the sensitive parameters and simulate scenarios for effective irrigation scheduling, site remediation, and risk assessment for better management plans.

\section{VI.CONCLUSIONS}

The impact of wastewater irrigation on soil with specific focus in emerging contaminant SDS dynamics in unsaturated soils was studied. The sorption, leaching and biodegradation mechanisms were studied in experimental soil columns and HYDRUS 1D model was developed for validation and scenario studies. It is concluded that the model is under predicted, the advection and dispersion phenomenon but matched well with the efficiency of $62.8 \%$ for biodegradation. The leaching potential of SDS is very high during the initial phase of experiment due to hydrophilic nature of SDS. The model was simulated for a scenario study to predict the transport of SDS for groundwater contamination at a depth of $30 \mathrm{~m}$. A concentration of $4.33 \mathrm{mg} / \mathrm{L}$ was observed at $30 \mathrm{~m}$ depth is indicated. As there were practices of wastewater irrigation everywhere, the impact of emerging contaminants to groundwater contamination can be studied using mathematical models and scenario studies can be done for planning better irrigation practices.

\section{REFERENCES}

1. APHA Standard Methods for Water and Wastewater Examination, 21st ed.American Public Health Association, Washington, DC,2005.

2. BIS, (Bureau of Indian Standards) .Specification for drinking water, IS:10500:91. Bureau of Indian Standards, New Delhi, 2003

3. Ramprasad, C and , Philip, L. Surfactants and personal care products removal in pilot scale horizontal and vertical flow constructed wetlands while treating greywater. Chemical Engineering Journal,2016,284, 458-468.

4. Ramprasad, C and , Philip, L. Contributions of various processes to the removal of surfactants and personal care products in constructed wetland, Chemical Engineering Journal,2018, 334, 322-333.

5. Simunek, J., Saito, H., Sakai, M., and Genuchten, T. M., The HYDRUS-1D software package for simulating the one-dimensional movement of water, heat, and multiple solutes in variably-saturated media ,University of California,2008.

6. P. Verlicchi , E. Zambello. Pharmaceuticals and personal care products in untreated and treated sewage Sludge. Science of the Total Environment ,2015,538,750-767.

7. C Mekala, Omkar Gaonkar, Indumathi M Nambi Understanding nitrogen and carbon biogeotransformations and transport dynamics in saturated soil columns , Geoderma,2017,285,185-194

8. Qing-Song Liu, Tong Zheng, Adsorption isotherm, kinetic and mechanism studies of some substituted phenols on activated carbon fibers Chemical Engineering Journal ,2010,157,348-356.

9. Yu-jie He, Wei Chen. Fate and removal of typical pharmaceuticals and personal care products by three different treatment processes. Science of the Total Environment,2013,447,248-254.

10. Osman Dumana, Erol Ayrancib. Adsorptive removal of cationic surfactants from aqueous solutions onto high-area activated carbon cloth monitored by in situ UV spectroscopy. Journal of Hazardous Materials,2010,174, 359-367.

11. Idil Arslan-Alaton_, Elif Erdinc, Effect of photochemical treatment on the biocompatibility of a commercial nonionic surfactant used in the textile industry. Water Research ,2006,40,3409 - 3418.

12. Raval Priti V, and Desai Hemangi H., Removal of Anionic Surfactant Sodium Dodecyl Sulphate (SDS) From Aqueous Solution By using Alumina, Journal of Environmental Research and Development,2012,7(2A), 851-862.

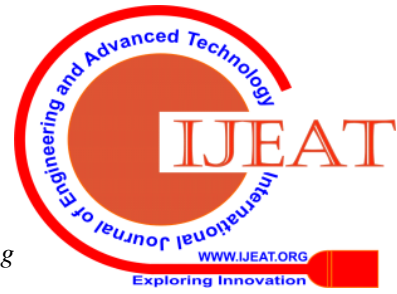


13. S. Harendra ,C. Vipulanandan, Determination of Sodium Dodecyl Sulfate (SDS) and biosurfactants Sorption and Transport Parameters in Clayey Soil. J Surfact Deterg,,2012, 15:805-813.

14. Simunek, J., van Genuchten, M.T., 2008. Modeling nonequilibrium flow and transport processes using HYDRUS. Vadose Zone Journal, Special Issue Vadose Zone Modeling, 2018,7(2),782-797.

\section{AUTHORS PROFILE}

Dr. P. Oliver jayaprakash, did his M.E.in Urban engineering from College of Engineering, Guindy, Anna University, Chennai in 1996. Further, He completed his Ph.D. Civil Engineering from Anna University Chennai in 2013. He is having more than 22 years of Teaching \& Research Experience to his credit. He is currently serving as Professor in Civil Engineering department of Sethu institute of Technology (Autonomous),Kariapatti

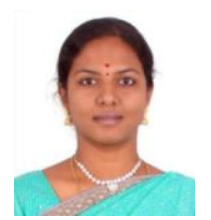

Dr. C. Mekala, did her M.E., Environmental Engineering \& Management in 2009 from Anna University and did her Ph.D. at IIT Madras, Chennai in 2017. She is the recipient of Government of India fellowship for Doctoral Research (2010-2015). She was Short listed for Women scientist A scheme from DST in 2019. She is having more than 9 years of Research Experience. She is currently working as Associate Professor in Civil Engineering at Sethu Insitute of Technology (Autonomous), Kariapatti

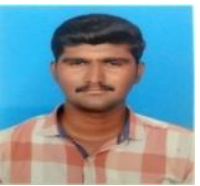

Er. M. Vishupriyan, is currently doing as research scholar in Civil Engineering department at Kamarajar College of Engineering \&Technology, Virudhunagar. 